\title{
In situ Measurement of Thermodiffusion in Liquid Alloys
}

\author{
E. Sondermann®, ${ }^{*}$ F. Kargl®, and A. Meyer® \\ Institut für Materialphysik im Weltraum, Deutsches Zentrum für Luft- und Raumfahrt (DLR), 51170 Köln, Germany
}

(Received 28 May 2019; published 20 December 2019)

\begin{abstract}
Temperature gradients can change the concentration distribution in multicomponent materials. This cross-coupling effect of heat and mass transfer is difficult to measure in liquid alloys. We present a new method using $\mathrm{x}$-ray radiography in combination with a high temperature furnace to measure thermodiffusion in melts time and space resolved. This greatly improves the process control and allows us to determine diffusion and thermodiffusion simultaneously. In a first experiment we demonstrate that in liquid $\mathrm{Al}_{78.5} \mathrm{Ni}_{21.5}$ the component nickel diffuses to the cold end of the sample with a Soret coefficient on the order of $10^{-3} \mathrm{~K}^{-1}$.

DOI: 10.1103/PhysRevLett.123.255902
\end{abstract}

Thermodiffusion (also called Soret effect or thermotransport) describes the formation of a concentration gradient induced by a temperature gradient in binary or multicomponent mixtures. This cross-coupling effect of heat and mass transfer plays a significant role in systems like petroleum reservoirs, aerosols, polymers and many others [1]. It has to be taken into account for the design of electronic devices [2] and nuclear reactors [3] and can be exploited for isotopic enrichment [4].

Extensive studies of thermodiffusion in organic mixtures are currently performed on ground as well as under microgravity aboard the international space station (ISS) [5-7]. Measurements under microgravity serve as benchmark because the influence of buoyancy-driven convection, which may destabilize the system, is reduced.

In granular media with particles of two different sizes, the larger or heavier particles are known to accumulate on the side with the lower granular temperature [8]. In binary liquid alloys, however, the heavier atoms do not always migrate to the cooler side of a temperature gradient [9]. In liquid $\mathrm{Na}-\mathrm{K}$, the direction of the thermodiffusion even changes with composition $[10,11]$.

Thermodiffusion in alloys can influence the homogeneity of grown crystals of a doped semiconductor [12]. During directional solidification of an alloy thermodiffusion can lead to a change of the concentration distribution and therefore alter properties of the solid [13-16].

Over the years, different theories were presented including self-contained theories and theories with a matching parameter [17,18]. However, reliable predictive theories for liquid alloys are still lacking. Recently, improved models were proposed [19], but experimental values needed to validate these models are scarce.

In addition, methods to calculate thermodiffusion by molecular dynamics were developed [20-23]. However, molecular dynamic simulations in liquid alloys can be very sensitive to the specific potential. Potentials that lead to essentially the same values for diffusion and thermal conductivity may even return opposite directions of thermodiffusion [24].

Only few measurements of the thermodiffusion coefficient in liquid alloys exist due to experimental difficulties at the required high temperatures. Usually the concentration profile of a sample in a temperature gradient is analyzed after solidification in order to determine the thermodiffusion coefficient experimentally [25-27]. In some cases the liquid sample is separated into several parts before cooling, therefore avoiding disturbances of the concentration distribution caused by the solidification process [28]. However, bubbles or free surfaces which cause Marangoni convection cannot be detected and may influence the measurement results.

We present a new technique which combines a vertical high-temperature furnace with x-ray radiography (XRR). The sample is exposed to a temperature gradient in the high-temperature furnace and x-ray images are recorded at different points in time. In binary alloys with sufficient contrast in X-ray absorption this method allows for in situ observation of the concentration profile. Thus, disturbances of the measurement by solidification are excluded and possible error sources such as free surfaces can be detected. Similar techniques were successfully employed for measurements of interdiffusion [29-31] and solidification [32] in binary liquid alloys.

In addition, the development in time is recorded without the need to extract sample material during the measurement. From the temporal evolution of the concentration profile, thermodiffusion coefficient and interdiffusion coefficient can be determined simultaneously.

To the best of our knowledge, $x$-ray radiography for the measurement of thermodiffusion was, up to now, only used for the determination of the final state of thermodiffusion in aqueous solutions around room temperature [33] but not for alloys and not for time-resolved analysis. X-ray 
radiography may be seen as equivalent to the in situ observation of the thermodiffusion process in transparent systems by optical interferometry [34].

To demonstrate the performance of the new technique we show a first measurement of thermodiffusion in liquid Al-Ni at $1398 \mathrm{~K}$. Al-Ni is a highly nonideal mixing binary system with sufficient contrast in X-ray absorption. Several computer simulations have been performed on diffusion and thermodiffusion in this system.

An $\mathrm{Al}_{78.5} \mathrm{Ni}_{21.5}$ sample was prepared from the pure elements (Al: $99.999 \%$ Hydro Aluminium, Ni: $99.995 \%$ Alfa Aesar) by arc melting and suction casting in a rodshaped copper mold in a high purity argon $(6 \mathrm{~N} \mathrm{Ar}+$ oxisorb $^{\mathrm{TM}}$ ) atmosphere. Homogeneity and absence of holes in the cast sample were verified by XRR.

Similar to measurements of self- and interdiffusion in liquids, it is important to prevent convection by a careful design of the furnace. As the setup has to be x-ray transparent, high-temperature stable, and no reaction between furnace and sample should occur, mainly alumina $\left(\mathrm{Al}_{2} \mathrm{O}_{3}\right)$ is used as construction material. The design of the here presented furnace is based on a setup for interdiffusion measurements in liquid alloys which proved to have a homogeneous radial temperature distribution [35]. This is necessary because radial temperature differences could lead to buoyancy-driven convection [36,37]. To minimize convection, a small sample diameter is preferable. Numerical simulations recommend a diameter of less then $2 \mathrm{~mm}$ [36]. Furthermore, the sample should be surrounded by the same material on all sides and no free surfaces or bubbles should occur to avoid convection caused by different surface tensions [38-40].

The rod-shaped alloy sample is contained in an aluminatube with an inner diameter of $1.6 \mathrm{~mm}$ and an outer diameter of $3 \mathrm{~mm}$. The liquid sample has a length of about $10 \mathrm{~mm}$. It is enclosed at both ends by movable alumina rods of approximately $2 \mathrm{~mm}$ length. To stop possible leakage, these are followed by movable graphite rods of approximately $2 \mathrm{~mm}$ length. A graphite piston, driven by a coil spring, presses on the upper graphite and alumina rod to ensure volume compensation during melting to avoid free surfaces or bubbles in the sample. Both above and below the position of the sample, a sheathed thermocouple type K of $0.5 \mathrm{~mm}$ diameter is fixed to the alumina tube to determine the temperature gradient.

The alumina tube containing the sample is placed in the center of a larger alumina tube (inner diameter $15 \mathrm{~mm}$ ) with two independently controlled heating zones. These heating zones consist of meandering molybdenum wires of $20 \mathrm{~mm}$ height with a distance of $28 \mathrm{~mm}$ positioned at the outside of the larger alumina tube. To ensure a smooth axial temperature gradient, a $0.1 \mathrm{~mm}$ niobium foil is placed between the tube and the heating wires. The wires are covered by alumina tubes for electrical insulation. Another $0.1 \mathrm{~mm} \mathrm{Nb}$ foil and $\mathrm{Al}_{2} \mathrm{O}_{3}$ felt of $2.5 \mathrm{~mm}$ thickness around the outer alumina tube are used for thermal insulation. The entire setup is mounted in a water-cooled vacuum-sealed aluminum housing. The housing features two aluminum windows with only $1 \mathrm{~mm}$ thickness each in the direction of the $\mathrm{x}$-ray beam. More details of the setup are given in the Supplemental Material [41].

An X-ray image of the furnace with a liquid $\mathrm{Al}_{78.5} \mathrm{Ni}_{21.5}$ sample is shown in Fig. 1. The sample which is enclosed by the alumina tube and upper and lower alumina pieces can be seen in the middle of the image. The positions of the two thermocouples, $\mathrm{TC} 1$ and $\mathrm{TC} 2$, and the heaters are also indicated.

After the assembly of the setup, the vacuum-sealed aluminum box is evacuated by means of a turbopump stage. The pressure in the chamber stays below $1 \times 10^{-3} \mathrm{mbar}$ during the entire experiment. Starting from room temperature the sample is heated to approximately $1460 \mathrm{~K}$ at a heating rate of about $3 \mathrm{~K} / \mathrm{s}$. Then a temperature gradient is established keeping the upper temperature (TC1) at $1423 \mathrm{~K}$ and the lower temperature (TC2) at $1373 \mathrm{~K}$. This is well above the liquidus temperature of $\mathrm{Al}_{78.5} \mathrm{Ni}_{21.5}$, which is about $1265 \mathrm{~K}$. After $70 \mathrm{~min}$ the temperature gradient is inverted. The temperature at the upper position is kept at $1373 \mathrm{~K}$ and at the lower position at $1423 \mathrm{~K}$ for another $54 \mathrm{~min}$.

At different points in time during the annealing, x-ray images are recorded with an exposure time of $5 \mathrm{~s}$. A microfocus x-ray source (XT9160-TED, Viscom) with tungsten target, operated at $140 \mathrm{kV}$ with $19.6 \mathrm{~W}$, and equipped with a $\mathrm{W}-\mathrm{Cu}$ aperture is used in combination with

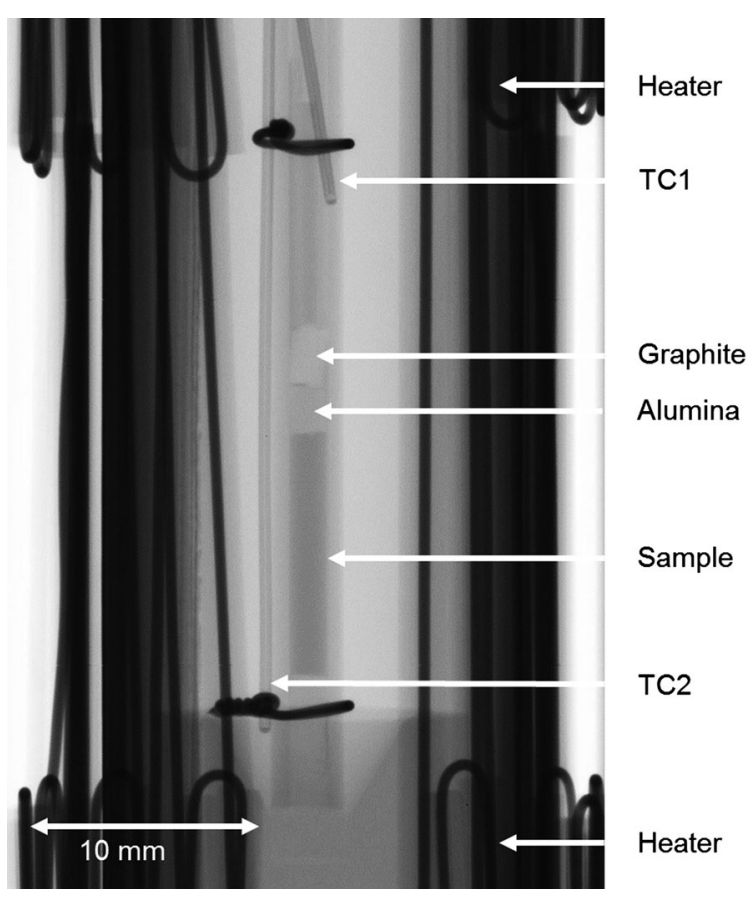

FIG. 1. X-ray image of the furnace with a liquid $\mathrm{Al}_{78.5} \mathrm{Ni}_{21.5}$ sample. 


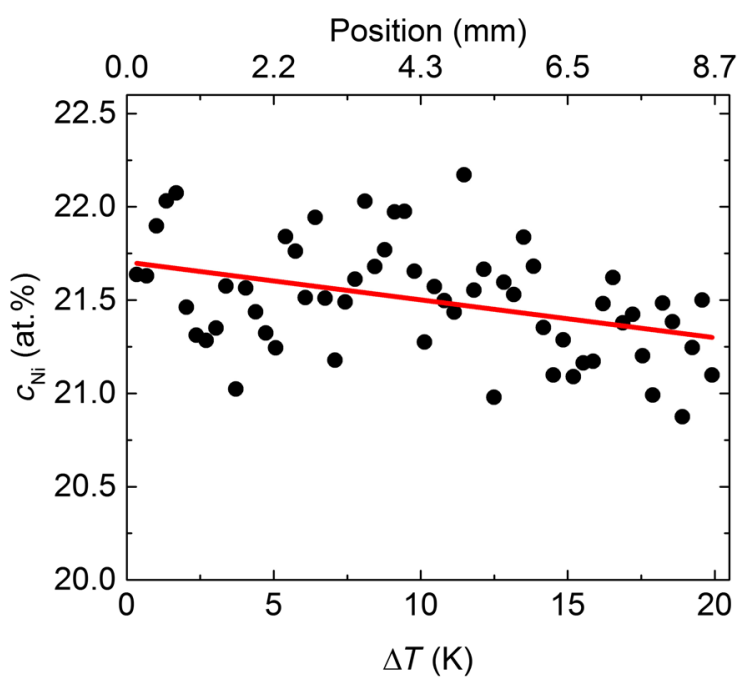

FIG. 2. Nickel composition as a function of position and temperature difference $4221 \mathrm{~s}$ after reaching a configuration where the top part of the setup is heated to $1423 \mathrm{~K}$ and the lower part is kept at $1373 \mathrm{~K}$. The data points are averaged over 10 images (equal to $50 \mathrm{~s}$ of recording) and 5 pixels $(0.145 \mathrm{~mm})$

the detector Shad-o-Box 2048 (Rad-icon). One pixel in the $\mathrm{x}$-ray images corresponds to $29 \mu \mathrm{m}$ in the place of the sample.

From the gray values of the $\mathrm{x}$-ray images, the nickel composition $c_{\mathrm{Ni}}$ along the sample is determined at different times. To do so, the gray values are averaged horizontally over the width of the sample. Afterwards, the gray values are averaged over 5 pixels, which corresponds to $0.145 \mathrm{~mm}$, in vertical direction and over 10 consecutive $\mathrm{x}$-ray images to reduce noise. The extinction of $\mathrm{x}$-rays is obtained by taking the logarithm of the gray value of the sample divided by the gray value of the background which is evaluated on the alumina tube. As Nickel absorbs more $\mathrm{x}$-rays then aluminum, a higher extinction corresponds to a higher Ni composition of the sample. We use a reference measurement in a comparable setup with samples of 18 and 22 at.\% $\mathrm{Ni}$ to calculate the $\mathrm{Ni}$ composition from the extinction.

The nickel composition as a function of position along the sample is shown in Fig. 2. It presents the situation $70 \mathrm{~min}$ after the temperature gradient in the top-hotconfiguration was established. Position 0.0 corresponds to the bottom of the sample. The position along the sample corresponds to a defined temperature difference $\Delta T$ which is also indicated. It can be seen that nickel tends to accumulate on the cooler side. To determine the concentration gradient the data are described by a linear fit which is shown as a red line.

Figure 3 shows the equivalent data $54 \mathrm{~min}$ after the temperature gradient was reversed. In this situation the upper part of the sample is cooler then the lower part. The slope of the linear fit is positive while in Fig. 2 it is negative. This means that independent of the direction of

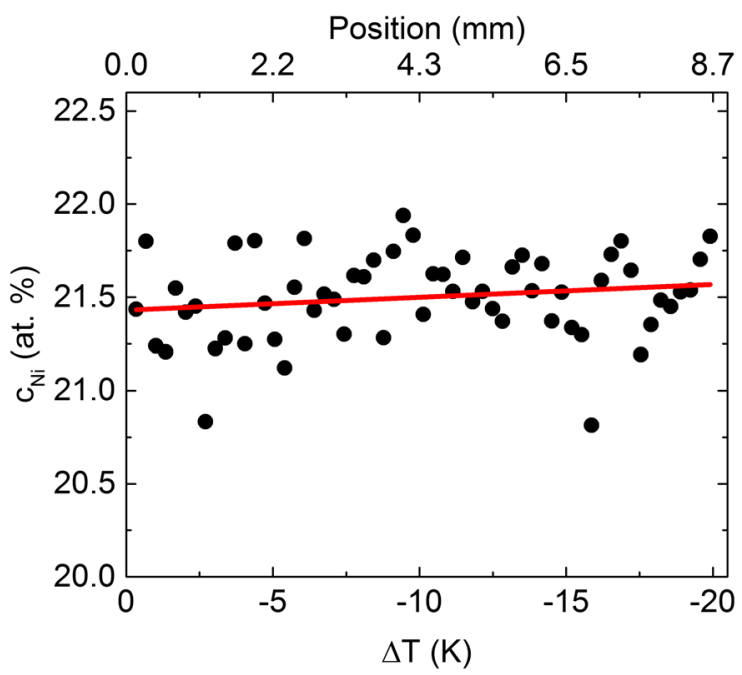

FIG. 3. Nickel composition as a function of position and temperature difference $3245 \mathrm{~s}$ after reaching a configuration where the top part of the setup is at $1373 \mathrm{~K}$ and the lower part is kept at $1423 \mathrm{~K}$. The data points are averaged over 10 images (equal to $50 \mathrm{~s}$ of recording) and 5 pixels $(0.145 \mathrm{~mm})$.

the temperature gradient with respect to gravity nickel in $\mathrm{Al}_{78.5} \mathrm{Ni}_{21.5}$ is always migrating to the cooler side.

Figures 2 and 3 display the distribution of nickel at one point in time. As x-ray images were recorded at different times during annealing we can also study its evolution in time. This is shown in Figs. 4 and 5.

Starting at the point when the temperature gradient is established, Fig. 4 displays the concentration gradient as a function of time. It evolves from -0.0075 at. $\% \mathrm{~K}^{-1}$ to about -0.025 at. $\% \mathrm{~K}^{-1}$.

In Fig. 5 the evolution of the concentration gradient is shown after the reversed temperature gradient is established. Due to the previous treatment, a concentration

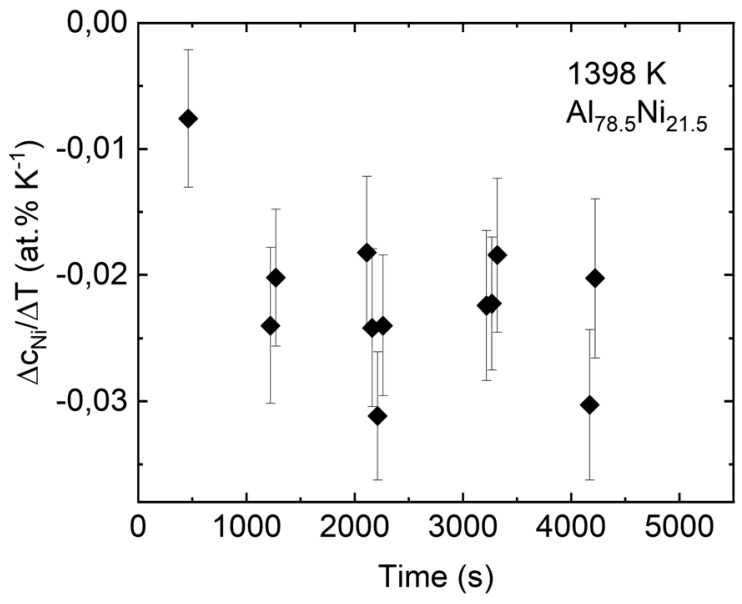

FIG. 4. Slope of the gradient in Nickel composition as a function of time in the top-hot configuration. The last data point on the right corresponds to the graph shown in Fig. 2. 


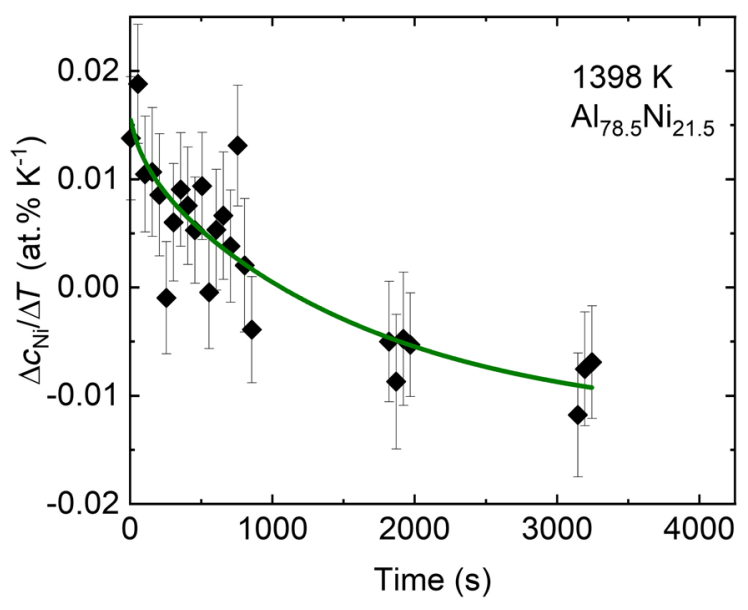

FIG. 5. Slope of the gradient in Nickel composition as a function of time in the top-cold configuration. The last data point on the right corresponds to the graph shown in Fig. 3.

gradient of about 0.017 at. $\% \mathrm{~K}^{-1}$ is still present. It gradually changes its direction and reaches a value of about -0.009 at. $\% \mathrm{~K}^{-1}$ after $3200 \mathrm{~s}$. The change of the concentration gradient is faster in the beginning and levels off at later times. A similar behavior was observed for an aqueous solution [42]. The concentration gradient that was reached with the higher temperature at the top is larger than in the case where the lower temperature is at the top. This might be caused by convection due to buoyancy.

The time to reach final state is estimated by Jesse [15] to be $\tau \approx\left(l^{2} / 2 D\right)$ where $l$ is the length of the capillary and $D$ the diffusion coefficient. With the length of the liquid sample $l=9.8 \mathrm{~mm}$ and a diffusion coefficient $D=7 \times 10^{-9} \mathrm{~m}^{2} / \mathrm{s}$, extrapolated from [43], the time to reach a steady state is $\tau=6860 \mathrm{~s} \approx 114 \mathrm{~min}$. This is longer then the time recorded in this experiment. Since the concentration gradient changes only marginally at later times, the concentration gradient obtained here is taken as an estimate for the final state. In general, the mass flux $J_{x}$ in a binary mixture is described by [44]

$$
J_{x}=-\rho D \frac{\partial c}{\partial x}-\rho D_{T} c_{0}\left(1-c_{0}\right) \frac{\partial T}{\partial x},
$$

where $\rho$ is the density of the mixture, $x$ the position, $c$ the concentration of one component, $c_{0}$ the average concentration of this component and $D_{T}$ is called thermodiffusion coefficient. When a final state is reached the mass flux is zero and the equation becomes

$$
\frac{\partial c}{\partial x}=-\frac{D_{T}}{D} c_{0}\left(1-c_{0}\right) \frac{\partial T}{\partial x} .
$$

The ratio $D_{T} / D=S_{T}$ is called Soret coefficient. In the following, we will use mole fractions although the concentrations in Eq. (1) originally refer to mass fraction. For binary mixtures the Soret coefficient does not change under the transformation from mole to mass fraction. The time dependence of the concentration in a temperature gradient is given by [44]

$$
\frac{\Delta c(t)}{\Delta T}=-S_{T} c_{0}\left(1-c_{0}\right)\left(1-\frac{8}{\pi^{2}} \sum_{\text {nodd }} \frac{e^{-n^{2}} \frac{t}{\theta}}{n^{2}}\right),
$$

with the characteristic time $\theta=l^{2} /\left(\pi^{2} D\right)$ where $l$ is the distance between the hot and the cold side of the sample. We will use the first five terms of the Fourier expansion following Costesèque et al. [42] who employed this method for an aqueous solution of $\mathrm{CuSO}_{4}$.

We use Eq. (2) to calculate the Soret coefficient for $\mathrm{Al}_{78.5} \mathrm{Ni}_{21.5}$ at $1398 \mathrm{~K}$. The concentration gradient $(-2.5 \pm 0.5) \times 10^{-4} \mathrm{~K}^{-1}$ in the top-hot-configuration results in $S_{T}=(15 \pm 3) \times 10^{-4} \mathrm{~K}^{-1}$.

Equation (3) allows us to determine the Soret coefficient and the diffusion coefficient simultaneously from the time dependence of the concentration gradient. In the case where the upper part of the sample is hotter than the lower part there are too few values at short times; therefore a meaningful fit is not possible. For the case where the temperature gradient is reversed a fit using Eq. (3) is shown in Fig. 5. Since the concentration gradient was not zero when the temperature gradient was established, an offset of 0.017 at. $\% \mathrm{~K}^{-1}$ was added. The fit yields a Soret coefficient of $(8 \pm 4) \times 10^{-4} \mathrm{~K}^{-1}$ and a characteristic time $\theta=(1650 \pm 840) \mathrm{s}$. This is slightly lower than the Soret coefficient obtained in the top-hot configuration but equal within error bars.

From the characteristic time and the length of the sample $l=9.8 \times 10^{-3} \mathrm{~m}$ a diffusion coefficient $D=$ $(6 \pm 3) \times 10^{-9} \mathrm{~m}^{2} / \mathrm{s}$ is obtained. This is compatible with measurements of the diffusion coefficient in Al-Ni [43].

Comparison to experimental observations of thermodiffusion in liquid Al-rich $\mathrm{Al}-\mathrm{Cu}$ [45] shows that in both alloys the heavier species migrates to the cold side. The mixing behavior of $\mathrm{Al}-\mathrm{Cu}$ is closer to ideal compared to Al-Ni. According to findings in Lennard-Jones mixtures [46], this should make the Soret coefficient of Al-Ni and its concentration dependence more pronounced compared to $\mathrm{Al}-\mathrm{Cu}$.

In earlier molecular dynamic simulations [23] nickel was found to migrate to the hot end in $\mathrm{Al}_{50} \mathrm{Ni}_{50}$. More recent molecular dynamic simulations using a Green-Kubo formalism and an improved potential find that in liquid $\mathrm{Al}-\mathrm{Ni}$ the component nickel strongly drifts towards the cold end for all concentrations of nickel [47]. This newer result is in accordance with our experiment.

Although the thermal conductivity is considerably lower in organic liquids compared to molten metals, their thermodiffusion coefficients fall into the same order of magnitude [44]. 
In summary, we presented the combination of a hightemperature furnace with $\mathrm{x}$-ray radiography for the measurement of thermodiffusion in liquid alloys. This method allows us to observe the evolution of the concentration gradient time and space resolved which greatly improves process control. In a first experiment, the thermodiffusion in liquid Al-Ni was measured. Irrespective of the direction of the temperature gradient, nickel always migrates to the cold side in $\mathrm{Al}_{78.5} \mathrm{Ni}_{21.5}$. The Soret coefficient is found to be in the order of $10^{-3} \mathrm{~K}^{-1}$. The time-resolved measurement of the concentration gradient allows us to determine the Soret coefficient and the diffusion coefficient simultaneously. The diffusion coefficient we obtained is compatible with data from literature. Further studies of the concentration dependence of thermodiffusion in liquid Al-Ni will show weather it depends only weakly on concentration as found in molecular dynamics or weather a strong concentration dependence is found in this highly nonideal mixture as findings from Lennard-Jones liquids suggest.

Further improvement of the setup should reduce the noise in the measured data. To reduce the influence of buoyancydriven convection, measurements of thermodiffusion in microgravity using $\mathrm{x}$-ray radiography are essential.

*elke.sondermann@dlr.de

[1] W. Köhler and K. I. Morozov, J. Non-Equilib. Thermodyn. 41, 151 (2016).

[2] C. Ru, J. Mater. Sci. 35, 5575 (2000).

[3] M. Sugisaki, K. Idemitsu, S. Mukai, and H. Furuya, J. Nucl. Mater. 104, 1493 (1981).

[4] A. Ott, Science 164, 297 (1969).

[5] T. Triller, H. Bataller, M. M. Bou-Ali, M. Braibanti, F. Croccolo, J. M. Ezquerro, Q. Galand, J. Gavaldà, E. Lapeira, A. Laverón-Simavilla, T. Lyubimova, A. Mialdun, J. M. O. de Zárate, J. Rodríguez, X. Ruiz, I. I. Ryzhkov, V. Shevtsova, S. V. Vaerenbergh, and W. Köhler, Microgravity Sci. Technol. 30, 295 (2018).

[6] A. Mialdun, J. C. Legros, V. Yasnou, V. Sechenyh, and V. Shevtsova, Eur. Phys. J. E 38, 27 (2015).

[7] S. Hartmann, G. Wittko, W. Köhler, K. I. Morozov, K. Albers, and G. Sadowski, Phys. Rev. Lett. 109, 065901 (2012).

[8] S. S. Hsiau and M. L. Hunt, Acta Mech. 114, 121 (1996).

[9] J. Praizey, Adv. Space Res. 6, 51 (1986).

[10] S. Murarka, T. Kim, M. Hsieh, and R. Swalin, Acta Metall. 22, 185 (1974).

[11] M. Eslamian, F. Sabzi, and M.Z. Saghir, Phys. Chem. Chem. Phys. 12, 13835 (2010).

[12] M. B. Sassi, S. Kaddeche, M. Lappa, S. Millet, D. Henry, and H. B. Hadid, J. Cryst. Growth 458, 154 (2017).

[13] E. Jafar-Salehi, M. Eslamian, and M. Saghir, Eng. Sci. Technol. Int. J. 19, 511 (2016).

[14] B. Bhat, J. Cryst. Growth 28, 68 (1975).

[15] R. E. Jesse, J. Cryst. Growth 5, 132 (1969).

[16] D. V. Alexandrov and D. L. Aseev, Comput. Mater. Sci. 37, 1 (2006).

[17] M. Eslamian and M.Z. Saghir, J. Non-Equilib. Thermodyn. 34, 97 (2009).
[18] M. Rahman and M. Saghir, Int. J. Heat Mass Transfer 73, 693 (2014).

[19] E. Jafar-Salehi, M. Eslamian, and M.Z. Saghir, Can. J. Chem. Eng. 92, 1314 (2014).

[20] S. H. Mozaffari, S. Srinivasan, and M. Z. Saghir, J. Therm. Sci. Eng. Appl. 9, 031011 (2017).

[21] B. Hafskjold, Eur. Phys. J. E 40, 4 (2017).

[22] W. C. Tucker and P. K. Schelling, Comput. Mater. Sci. 124, 54 (2016).

[23] A. V. Evteev, E. V. Levchenko, I. V. Belova, R. Kozubski, Z.-K. Liu, and G. E. Murch, Philos. Mag. 94, 3574 (2014).

[24] E. V. Levchenko, A. V. Evteev, T. Ahmed, A. Kromik, R. Kozubski, I. V. Belova, Z.-K. Liu, and G. E. Murch, Philos. Mag. 96, 3054 (2016).

[25] B. Bhat and R. Swalin, Acta Metall. 20, 1387 (1972).

[26] S. Van Vaerenbergh, J. P. Garandet, J. P. Praizey, and J. C. Legros, Phys. Rev. E 58, 1866 (1998).

[27] M. Balourdet, Y. Malmejac, and P. Desre, Phys. Lett. A 56, 51 (1976).

[28] J. Praizey, S. V. Vaerenbergh, and J. Garandet, Adv. Space Res. 16, 205 (1995), microgravity Sciences: Results and Analysis of Recent Spaceflights.

[29] B. Zhang, A. Griesche, and A. Meyer, Phys. Rev. Lett. 104, 035902 (2010).

[30] A. Griesche, B. Zhang, E. Solórzano, and F. Garcia-Moreno, Rev. Sci. Instrum. 81, 056104 (2010).

[31] E. Sondermann, N. Jakse, K. Binder, A. Mielke, D. Heuskin, F. Kargl, and A. Meyer, Phys. Rev. B 99, 024204 (2019).

[32] M. Becker, S. Klein, and F. Kargl, Scr. Mater. 124, 34 (2016).

[33] S. Rondot, O. Aaboubi, P. Baudart, D. Erre, E. Mrienne, and J. M. Patat, Eur. Phys. J. Appl. Phys. 17, 75 (2002).

[34] A. Mialdun and V. Shevtsova, J. Chem. Phys. 134, 044524 (2011).

[35] F. Yang, P. Heintzmann, F. Kargl, K. Binder, B. Nowak, B. Schillinger, T. Voigtmann, and A. Meyer, Phys. Rev. B 98, 064202 (2018).

[36] J. P. Garandet, J. P. Praizey, S. Van Vaerenbergh, and T. Alboussiere, Phys. Fluids 9, 510 (1997).

[37] J. I. D. Alexander, J.-F. Ramus, and F. Rosenberger, Microgravity Sci. Technol. 9, 158 (1996).

[38] F. Kargl, E. Sondermann, H. Weis, and A. Meyer, High Temp.-High Pressures 42, 3 (2013).

[39] X. Ruiz and J. Pallars, Microgravity Sci. Technol. 23, 173 (2011).

[40] S. V. Vaerenbergh, J.-C. Legros, and J.-C. Dupin, Adv. Space Res. 16, 69 (1995), eURECA Scientific Results.

[41] See the Supplemental Material at http://link.aps.org/ supplemental/10.1103/PhysRevLett.123.255902 for a detailed description of the setup.

[42] P. Costesèque, T. Pollak, J. K. Platten, and M. Marcoux, Eur. Phys. J. E 15, 249 (2004).

[43] E. Sondermann, F. Kargl, and A. Meyer, Phys. Rev. B 93, 184201 (2016)

[44] J. K. Platten, J. Appl. Mech. 73, 5 (2006).

[45] B. Bhat, National Aeronautics and Space Administration, Technical Report No. TR R-415, 1973.

[46] P.-A. Artola and B. Rousseau, Phys. Rev. Lett. 98, 125901 (2007).

[47] T. Ahmed, W. Y. Wang, R. Kozubski, Z.-K. Liu, I. V. Belova, and G. E. Murch, Philos. Mag. 98, 2221 (2018). 